\title{
Vulvar Myiasis in Early Pregnancy
}

Jha $R^{1}$, Upadhyaya $I^{1}$, Thapa $M^{1}$, Awal $R^{2}$

Department of Obstetrics and Gynecology, Paropakar Maternity and Women's Hospital, Kathmandu, Nepal

Received: December 2, 2015 ; Accepted: February 8, 2016

Myiasis is a parasitic infestation caused by the larvae of several fly species in various body wound and orifices. Vulvar myiasis is an extremely rare location. This is a case report of a 25 years old pregnant lady who presented with signs of burning sensation, itching and irritation invulval area. Vulval inspection revealed an ulcer on mons pubis with induration and tiny maggots crawling over the ulcer. She was managed conservatively with daily dressing and manual removal of larva along with vaseline gauge packing and application of topical antimicrobials as well as prophylactic systemic antibiotics. The wound was left to heal by secondary intention. Patient was discharged after 7 days of hospital stay with advice on personal hygiene to avoid reinfection.

Keywords: External genitalia;maggots;myiasis;pregnancy.

\section{INTRODUCTION}

Myiasis is derived from the Greek word-"Myia", meaning "fly" and is defined as a disease caused by the infestation of dipterous larvae in various body wounds and orifices. ${ }^{1,2}$ Single female fly deposits 4080 first stage larva, which can enter through intact skin or through a wound in small neglected children, very old patients, mentally retarded, bedridden patients who are not able to take care of themselves. In young, mentally healthy and active persons it is rare to see maggots. ${ }^{1}$ The location of this infestation at the vulvar area is however, an extremely rare occurrence and constitutes only $0.7 \%$ of human infestation. ${ }^{3}$ The published cases of genital myiasis are nevertheless very few ${ }^{4-7}$ and rarely reported with pregnancy. ${ }^{8}$

Here, we report a pregnant lady at $13^{\text {th }}$ week of gestation who was found to have vulvar myiasis and was successfully managed conservatively.

\section{CASE}

A 25 years old pregnant lady at 14 weeks of gestation from lower socioeconomic back-ground presented to our gynaecological outpatient department with complains of amenorrhea for 3 months, burning sensation in vulva with on/off vulvar pain for 1 month, itching and irritation in vulva with whitish

\section{CORRESPONDENCE}

Dr Indira Upadhyaya

Email: drindira@hotmail.com

Paropakar Maternity and Women's Hospital,

Kathmandu, Nepal discharge from vagina for past 5 days. She was from rural Udaypur, Nepal and was accompanied by her husband. She was noted to have poor hygiene wearing dirty clothes. She reported that at her home she had unhygienic washroom outside the house which attracted many flies. She had normal regular menstrual cycle prior to this pregnancy. Patient did use readymade sanitary napkins available in the market during the menstrual periods. She used to hang the washed clothes and undergarments on a clothes line outside. There was history of insect bite, and sexual activity one week back. There was no history of pain in the lower abdomen. No history of intake of any immunosuppressive or steroidal therapy. She also denied history of any chronic illness including tuberculosis, chronic urinary tract infection, and diabetes. Physical examination of the patient revealed a normal build (height 5 feet 2 inches, weight 52 $\mathrm{kg}$ ) with vitals in normal range. On examination she was ill looking. Examination of the vulva with consent revealed an ulcer of $2 \times 3 \mathrm{cms}$ on the middle of the mons pubis with induration and edema around the ulcer. Further close examination revealed tiny crawling maggots of creamy-white color measuring about 2 to $4 \mathrm{~mm}$ coming out of the ulcer (Figure 1A). On speculum examination, cervix and vagina were healthy and on per vaginal examination uterus was 12 wks size, os- closed.

Laboratory investigations revealed hemoglobin-12.6 $\mathrm{gm} / \mathrm{dl}$, with a normal leucocytes count and urine 
routine examination. Her random blood sugar was $84 \mathrm{mg} \%$,serology for HIV (Human immunodeficiency virus),HBsAgand Syphilis (by Venereal Disease Research Laboratory test) were negative. Wound swab staining and culture showed no evidence of any bacterial or fungal growth. Her abdominal sonography revealed single live fetus with breech presentation at 13 weeks of gestation and placenta anterior low lying. She was kept on prophylactic IV antibiotics. On same day after giving oral analgesic ulcer was cleaned with hydrogen peroxide and normal saline, maggots started coming out and about 15-18 maggots were picked up with forceps . Following day her symptoms was improved. On second day of admission 5 maggots were picked up with forceps and the wound was again cleaned with hydrogen peroxide ,betadine and vaseline pack was kept. On the next day we again found around 3 maggots which were removed but this time the maggots were larger than the previous ones and measured about $3 \times 6 \mathrm{~mm}$. Everyday dressing was done with hydrogen peroxide then topical ointment of metronidazole applied and packed with vaseline gauze. On the $4^{\text {th }}, 5^{\text {th }}, 6^{\text {th }}$ and $7^{\text {th }}$ day maggots were completely absent. The ulcer had healthy granulation tissue. The wound was left to heal by secondary intension (Figure 1B). Patient remained in the hospital for 7 days and was discharged with advice on personal hygiene to avoid reinfection.

\section{COMMENT}

This is the second case report of vulvar myiasis during pregnancy. ${ }^{8}$ In contrary to the patient reported previously by Passos et al. ${ }^{8}$ the testing for HIV and syphilis were negative. We postulate poor personal hygiene, poor living condition and unhygienic surrounding and wash room probably would have contributed to myiasis in our patient.

Human myiasis is caused by fly larvae capable of penetrating body orifices as well as healthy or necrotic tissue. The fly species that infest healthy tissue are called Biontophage and are responsible for the cutaneous form of this condition (furunculoidmyiasis). Among these species the most frequent are Dermatobiahominis, Cochliomyiahominivorax and Oestrusovis. The species that infest necrotic tissue (cavitarymyiasis) include the genus Sarcophaga, Lucilia, Callitroga and Musca, as well as the Muscafannia species. ${ }^{9}{ }^{10}$ Sherman recommended that maggots should be sent for species identification. ${ }^{3}$ Unfortunately, species identification was not possible in our patient because of unavailability of the facility in our area.

Human myiasis can be classified as cutaneous myiasis, ocular myiasis, urogenital myiasis and intestinal myiasis based on clinical presentation. ${ }^{11}$ In the primary and furunculoid forms of the disease the larvae penetrate the skin,leading to the formation of painful, inflammatory nodules that can form fistula to internal organs or to the surface of the skin. ${ }^{3}$ Prognosis is generally good, treatment consists of removal of the parasitic larvae and through cleansing of affected area. Some complications have already been documented, such as secondary infection and tetanus. ${ }^{3}$ The possible source in the present case may be the eggs, which were transmitted to the vulva via soiled clothes. The flies laid eggs when the undergarment was on clothes line as flies were attracted to the blood and body secretions. Myiasis occurs predominantly in rural areas and is associated with poor hygiene practices and low education level. ${ }^{1}$ As poor hygiene is known to be associated with vulvar myiasis, washing and keeping the genital area clean may prevent to a great extent the occurrence of this condition. ${ }^{12,13}$ In a multi-center study of American patients who were infected with maggots, 42 cases of myiasis were identified with male predominance and $38 \%$ were homeless. $^{3}$

To conclude, vulvar myiasis in external genitalia is a rarely reported condition during pregnancy. This case highlights the need for thorough genital examination as a means of identifying less common disease. Role of physician's is to educate patient (especially those living in rural area) is important and must emphasize the role of good personal hygiene.

\section{DISCLOSURE}

The authors report no conflicts of interest in this work.

Ethical Statement: Written consent has been obtained from patient.

Funding: Nil 


\section{REFERENCES}

1. Kataria U, Siwach S, Gupta S. Myiasis in female external genitalia . Indian J Sex Transm Dis. 2013;34: 129-31.

2. Raja AM, Vidhyashree, Pushpa Kotur P. Vulvalmyiasis in rural setting: a case report. Int J Adv Res. 2014;2: 422-4.

3. Sherman RA. Wound myiasis in urban and suburban United States. Arch Intern Med. 2000;160: 2004-14.

4. J Deus MCBR, Santos JA, Quevedo JMA. Vulvar myiasis [Portuguese].Femina 1989;17:560-

5. Gomes PA, Fukugava MFN, Cuce LC. Vulvar myiasis. J Bras Med. 1996;70: 106-8.

6. Delir S, Handjani F, Emad M, Ardehali S. Vulvar myiasis due to Wohlfahritia magnifica. Clin Exp Dermatol. 1999;24: 27980 .

7. Passos MR, Carvalho AV, Dutra AL, Goulart Filho RA, Barreto NA, Salles RS et al. Vulvar myiasis. Infect Dis Obstet Gynecol. 1998;6: 69-71.
8. Passos MRL, Varella RQ, Tavares RR, Barreto NA, Santos CCC, Pinheiro VMS et al. Vulvar myiasis during pregnancy. Infect Dis Obstet Gynecol. 2002;10: 153-8.

9. Cilla G, Picó F, Peris A, Idígoras P, Urbieta M, Pérez Trallero E. Human genital myiasis due to Sarcophaga. Rev Clin Esp. 1992;190:189-90.

10. Perez-Eid C, Mouffok N. Human urinary myiasis caused by Fannia canicularis (Diptera, Muscidae) larvae in Algeria. Presse Med. 1999;28: 580-1.

11. Janovy J Jr, Schmidt GD, Larry S. Gerald D. Schmidt and Larry S. Roberts' Foundations of Parasitology. Dubuque, Iowa: Wm. C. Brown; 1996. 12. Predy G, Angus M, Honish L, Burnett CE, Stagg A. Myiasis in an urban setting: a case report. Can J Infect Dis. 2004;15: 51-2.

12. Yazar S, Ozcan H, Dinçer S, Sahin I. Vulvar myiasis. Yonsei Med J. 2002;43: 553-5. 